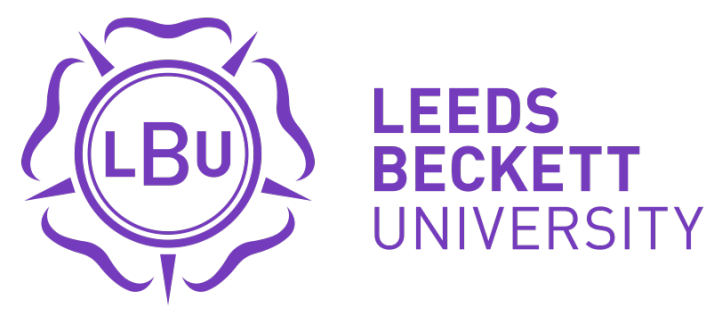

Citation:

Long, J (2016) Living with the consequences of policy decisions: reactions to student lifestyles in the neighbourhood. Journal of Policy Research in Tourism, Leisure and Events, 8 (2). pp. 176-195. ISSN 1940-7963 DOI: https://doi.org/10.1080/19407963.2016.1157599

Link to Leeds Beckett Repository record:

https://eprints.leedsbeckett.ac.uk/id/eprint/2327/

Document Version:

Article (Accepted Version)

The aim of the Leeds Beckett Repository is to provide open access to our research, as required by funder policies and permitted by publishers and copyright law.

The Leeds Beckett repository holds a wide range of publications, each of which has been checked for copyright and the relevant embargo period has been applied by the Research Services team.

We operate on a standard take-down policy. If you are the author or publisher of an output and you would like it removed from the repository, please contact us and we will investigate on a case-by-case basis.

Each thesis in the repository has been cleared where necessary by the author for third party copyright. If you would like a thesis to be removed from the repository or believe there is an issue with copyright, please contact us on openaccess@leedsbeckett.ac.uk and we will investigate on a case-by-case basis. 


\title{
Living with the Consequences of Policy Decisions: Reactions to Student Leisure Lifestyles in the Neighbourhood
}

Jonathan Long, Research Institute for Sport, Physical Activity and Leisure, Leeds Beckett University, UK.

\begin{abstract}
A national (UK) policy to expand higher education has changed the demographic composition of communities in many university towns and cities and the social forces operating thereon. As the economy and services adapt, those already resident in such areas may be quite comfortable accommodating the changes. Those who are not may leave (exit/flight) or stay and either 'hunker down' (loyalty) or act to protect what it was they had come to value about the area (voice). The case examined here is that of a part of Leeds where the consequent 'studentification' prompted the exit of many residents, thereby making way for further students. Some residents, with strong roots in the area, remained loyal and it is their views, along with those of business people, councillors and others, that are examined in this paper. This study of reactions to student lifestyles was initially prompted by Cohen's notion of 'moral panic' that gradually revealed a contestation over the right to determine the character, the soul, of the area. In so doing it considers how, as soft or symbolic power ebbed, attempts were made by local residents to shape a policy response. However, in that arena too, the locus of control is shown to be elusive.
\end{abstract}

\section{Introduction}

This paper was stimulated by the recent special issue of the journal devoted to alcohol and moral panics ${ }^{1}$. It examines the processes associated with an adverse reaction of a community to the local consequences of a national policy designed to facilitate a large increase in the number of people in higher education. The paper broadly follows the course of a small-scale research project. At first sight the community response appears to have many of the components of a moral panic (Cohen, 1972), but an inspection of events alongside a consideration of the literature on moral panics indicates greater complexity. Subsequent, more detailed empirical investigations then demonstrate the importance of considering the differential operations of power.

For more than two decades higher education (HE) policy in the UK has been geared towards larger and larger numbers of students, justified as necessary to produce the skills required in a post-industrial economy. What has received rather less attention in policy discourses has been the consequence students have for the communities in which they temporarily live. By focusing here on relationships between students and long-term residents the paper makes a contribution to the gap remarked by Smith (2009, p. 1795):

it is unclear how enlarged student populations intersect with broader societal trends such as rising levels of population transience and density, mobile societies, social conflicts tied to lifestyle clashes, the disintegration of 
community cohesion and interaction, decreasing expressions of social capital, detachment from local places, and lost senses of belonging.

An examination of reactions to a high concentration of students in a residential neighbourhood of Leeds, a large UK city, provides the basis for a consideration of whether what has been witnessed constitutes a moral panic triggered by leisure lifestyles that offend. The contention is that a proper understanding requires us to look beyond that framework to consider other social and policy changes and how people seek to exercise control over their lives, in part by shaping their neighbourhood.

\section{Moral Panic}

Thompson (1998, p. 1) boldly opened with the claim that 'it is widely acknowledged that this is the age of the moral panic'. As in this paper, he took his lead from Cohen's concept of 'moral panic' which was classically introduced as:

A condition, episode, person or group of persons emerges to become defined as a threat to societal values and interests; its nature is presented in a stylized and stereotypical fashion by the mass media; the moral barricades are manned [sic] by editors, bishops, politicians and other right-thinking people; socially accredited experts pronounce their diagnoses and solutions; ways of coping are evolved or (more often) resorted to; the condition then disappears, submerges or deteriorates and becomes more visible (Cohen, 2002, p. 1).

Essentially a moral panic reflects an attempt to regain control in the face of something that is seen as threatening to disrupt an established balance of power. Five key elements of such moral panics were identified (Cohen, 2002, xxii). First comes a concern about the 'threat' [here seen as the takeover by students not prepared to comply with normal expectations of appropriate behaviour]. Second, is hostility as moral outrage towards 'folk devils' and the agencies who are ultimately responsible [in this case the universities as well as the students]. Third, consensus forms around widespread acceptance that the threat exists and that 'something should be done' [here reflected in the common acceptance of the derogatory collective term, 'student']. Fourth, there is disproportionality in the exaggeration of damage/offensiveness/risk. Fifth, they are volatile, erupting and dissipating suddenly.

As identified by the second point, 'moral panics are generated around folk devils, mythologised scapegoats who are marginalised and Othered' (Spracklen, 2014, p.140). Cohen suggests that the moral outrage may not only be directed at these scapegoats, but also at the agencies ultimately responsible. However, as Spracklen (2014) points out, such agencies (the universities and sometimes the city council) are themselves subject to more distant levers of power.

Notably Cohen (2002, p. vii) commented:

Calling something a 'moral panic' does not imply that this something does not exist or happened at all and that reaction is based on fantasy, hysteria, delusion and illusion or being duped by the powerful [emphasis added]. 
Equally, he was not particularly interested in making judgements about whether something was or was not 'bad', but with the dynamics of the associated social processes that led to it being constructed in this way. However, as already identified, his model does present the response as disproportionate, though that too has been challenged (e.g. Thomson, 1998). In this paper there is no attempt to arbitrate on proportionality; the concern is with the social processes at play and with the insistence on volatility (point 5 above). The moral panic thesis suggested that the phenomenon moved rapidly from something/someone being defined as a threat and depicted in the media, through a rapid escalation of public concern bringing a response from the authorities, to the panic receding or social changes being instituted. In the case examined here, the original 'panic' built-up over a few years and has shown little sign of abating over the subsequent twenty.

The project started with the intention of using the moral panic thesis to examine the nature of responses to a significant community shift and how these might operate over an extended timescale well beyond that envisaged by Cohen. The reaction of the community considered here certainly has echoes of Cohen's concept of 'moral panic', though evidence will suggest that the model does not quite fit. Cohen's interest was in panics that swept the country, fuelled by national media, and then died away within a matter of months; although there are parallel instances to the subject of this paper around the country they are all localised. Crucially, just as Cohen (2002) acknowledged that his original thesis would benefit from a closer consideration of power, the emphasis of this paper gradually changed in response to the analysis of what participants in the research had to say and as indicators of social processes became more evident.

\section{Moral Panic, Students and Leisure}

Cohen (1972, p. 9) suggests that society has a set of pre-conceptualised images of who 'constitutes the typical deviant', and that 'the objects of normal moral panics are rather predictable' (2002, p. viii). Students may seem an unlikely haunt of 'respectable fears' (Pearson, 1983), especially as, in this case, many of the residents were themselves students and/or have sons and daughters who are/were students (unlike the class divisions observed by Holt and Griffin, 2005). However, DeJong and Vehige (2008, p. 1), writing for the US Higher Education Center for Alcohol and Other Drug Abuse and Violence Prevention, recognise how this might happen.

Unfortunately, students often keep late hours, and their everyday comings and goings may disturb neighbors who are trying to work, sleep, or just enjoy a quiet evening at home. When alcohol is served, house parties can easily get out of control, leading to large crowds, blocked driveways, litter, excessive noise, public intoxication, public urination, and vandalism.

While individuals and individual incidents are insufficient to engender a panicky response, accumulations might (e.g. Allinson, 2006; Selwyn, 2008; Munro, Turok, \& Livingston, 2009). Leeds and its universities have embraced the image of a city supporting a lively leisure scene. Locally, the carnivalesque Otley Run (a formalised route for a pub crawl) has become renowned and commercial interests are happy to 
extend and exploit the connection between student lifestyles and alcohol with questionable promotions and events (e.g. Carnage and Tequila UK's 'Fresher's Violation'2) fuelling images of carnivalesque hedonism (Hubbard, 2013) that are seen to be 'de-moralising' (Crawford and Flint, 2009). Critical responses are not simply the product of sensational journalism; the National Union of Students (Phipps \& Young, 2012, p. 28) reported that student culture is 'significantly shaped by alcohol consumption'. Although students are not normally considered a physical threat (though some research participants did see them in such terms), they are still seen as a threat to 'the moral order of the street' (Valentine, 2001, p. 180).

Similarly, at first sight leisure might seem to be a peculiarly innocuous area for generating a moral panic, but it carries so much significance in representing one's chosen identity (as opposed to imposed elements) that the potential for disagreement, contestation, denigration and challenge is clear. Nonetheless, leisure researchers have exercised caution in considering the basis of concern for processes they review in the context of moral panics. For example, the bases of moral panics in relation to 'football hooligans', 'couch kids', child abuse in sport, and young people at risk through binge drinking, have been questioned by Redhead (2007), Biddle et al. (2004), Brackenridge (2001, 2002) ${ }^{3}$, Hickey et al. (2009), respectively. Valentine et al. (2008, p. 28) are equally cautious, arguing that moral panics about binge drinking are implicitly producing a monolithic image of alcohol consumption in urban areas that fails to acknowledge the socio-spatially differentiated nature of practices of alcohol consumption and regulation'. While they found that the local council in their rural area subscribed to views similar to those of the moral panic represented in the media, the general population did not. Instead of the associations with public disorder in an urban context, they constructed the drinking behaviour of local youngsters as 'a normal, socially acceptable, and even banal part of the life course' (p. 35).

\section{Background to the Study}

Although also involving surrounding areas of Leeds, it is Headingley and Hyde Park that is the area identified in the popular imagination with students ${ }^{4}$. This has long been the case, but has been emphasised by the expansion of HE in the UK.

Reference to the author's research diary provided a reminder that markers had been identified even before the major growth: an estate agent advised, "That's in Headingley - you won't want to be with the students". One of the consequences of the policy of the New Labour government (1997-2010) to increase the proportion of people experiencing higher education to $50 \%$ was to shift the balance of population in parts of most of the country's cities. While exercising some caution the subsequent coalition government did not reverse that position, though making students responsible for the full cost of their education initially put a brake on the growth.

$<<$ Figure 1 about here $>>$

Figure 1 shows that the number of full-time undergraduate students studying in the UK increased by 49\% in the 17 years between 1994/5 and 2011/12 (Higher Education Statistics Agency (HESA) data published on line at the time of the project). With the introduction of full student fees the number subsequently fell in 
$2012 / 13$, but rose again in $2013 / 14$. The growth has been greater in Leeds where HESA data for what are now the three universities show a 62\% (17048) increase over the slightly shorter period of 1995/6-2011/12.

The universities in Leeds did not match that growth in student numbers with a corresponding increase in university accommodation. So with the main campuses of two big universities being located adjacent to each other there is a high spatial concentration of demand for private sector student accommodation. Using census data the Leeds $\mathrm{HMO}^{5}$ lobby calculated that in 1991, students constituted c. $20 \%$ of the population of Headingley Ward and that by 2001, this had risen to $61 \%$ (Leeds HMO Lobby, 2005). The 2011 Census subsequently showed a further increase to two thirds of the local population. Largely because of the concentration of students in Headingley, the pattern in Leeds was the second most concentrated in the country (Munro et al., 2009). It is this concentration that has been referred to as 'studentification' (e.g. Smith, 2008, 2009), something that creates new processes of urban change (Allinson, 2006; Hubbard, 2008).

This both precipitated and was facilitated by people moving out of the Headingley area. One research participant noted:

...the rate at which people were leaving central Headingley. You'd bump into people every day saying 'Oh l've put my house on the market, can't stand it, I'm not living next door to students' and so the flight was really, really noticeable.

It is this exodus and the nature of exchanges between Headingley residents about students that is suggestive of a panic.

Alongside that policy commitment to increasing the numbers accessing $\mathrm{HE}$, it is also important to acknowledge other cotemporaneous policies. Particularly notable in this context were efforts to rebrand Leeds as a regional European capital. The reimaging of Leeds was as a 24-hour city with a night time economy supported by clubs and extended licences (e.g. Bramham \& Spink, 2009). The growing numbers of students may not have been popular with some local residents, but they played a significant part in realising that ambition in addition to securing the economic viability of the universities (they and some local businesses were certainly economic beneficiaries). This is underpinned by 'the growth of easy credit for students that has underpinned the growth of the consumption-oriented student city' as part of neoliberalism (Chatterton, 2010, p. 511).

\section{The Leeds Study}

This paper examines a local response to a national policy (HE expansion) and the consequent pressure for measures of remedy/redress. The concern is not with identifying what percentage of local interests are (not) opposed to some aspect of student lifestyles in the neighbourhood. Instead the focus is on how people try to understand the social processes involved and the inter-relationships with policy and subsequent interventions. 
This small scale, qualitative study involved in-depth, face-to-face interviews with local residents (8), student representatives (3), people in the business community (4), elected representatives (3) and others with specific responsibilities (a police liaison officer and a university officer with responsibility for a neighbourhood helpline). These were conducted in venues convenient for the respondents between mid-2013 and early 2014, using a semi-structured interview schedule. At the end of the interview participants were asked for signed consent and invited to choose a pseudonym to offer anonymity. To distinguish them from quotes from the literature the words of research participants are either enclosed in double quotation marks or appear in italics. The interviews are set against the backdrop of a reading of assorted local policy and planning documents and monitoring email exchanges on the various local networks (supplemented by a research diary and more than 25 years of observation). The process of coding the data followed the lead of Strauss and Corbin (1990) in considering: the phenomenon being researched; contextual/situational conditions; actions taken to deal with the phenomenon; and consequences.

Given the important role the media are seen to play in Cohen's conception of moral panics (see also Critcher, 2006), representations of students in the local press (Yorkshire Evening Post) were also examined. However, this document search suggested that the press has been quite restrained, carrying only occasional antistudent articles and sometimes positive ones. Moreover, some of the negative articles are directed at providers like organisers of events or landlords. In Hier's (2002) eyes this is perhaps an advantage as it means our assessment is not distracted by media sensationalism. In recent years though, local residents have been able to use electronic media to communicate, particularly through an email network ${ }^{6}$. The consequence of any form of media activity is that people become more sensitive to incidents so that what might have gone unremarked is lent heightened significance.

Prior to considering the policy responses it seems appropriate to give voice to some of the concerns of local residents.

\section{Student Living and Living with Students}

\section{"Students"}

The student representatives were concerned at the common negative stereotype of 'students' and were anxious to demonstrate how much they contributed to the city. Certainly, the business owners were favourably disposed towards students, being keen to welcome them back from their holidays; indeed some had chosen to locate in Headingley because of what they bring to the area. In stark contrast, the social media of local residents has carried invective towards 'students', though for the most part local respondents gave a more nuanced response. Many insisted they liked students (one even thought some of them were "sweet") and the most common descriptor of Headingley was "vibrant" (to which students are seen to contribute), but the same person could point out that counted for little when faced with repeated antisocial behaviour. 
There is little doubt that some living amongst the student houses have experienced trying times. It can then be difficult to avoid an emotional response. For example, Reg, questioned, "Why should we be pushed out by these stupid, bumptious, selfimportant young twerps who are only here for a short time?" That was followed almost immediately by the more considered: "Students individually are like anybody else. They can be pillocks, but most of them are OK and some of them are terrific." And then the despairing: "But en masse..." And Bob offered an assessment that will have familiar echoes for those researching football fans: "There are lots of things that are really good about students in the area but there's a minority that give the majority a bad name". Pursuing the same idea of a minority, Sue's assessment was that there is an "anti-social, inconsiderate, pain in the arse minority... but a minority of a massive number is still a lot of people to deal with".

There is clearly a geographical component to this too. Those living on the periphery may experience a group of bad students one year and then have several years respite. For others the distress may be more persistent if they live on one of the favoured through routes between bars or routes home, or if they live in a street with so many houses that when a group of 'bad' students moves out of one house a different group of 'bad' students may move into one of the other twenty nearby.

\section{Causes of aggravation}

Like many others, when asked about the most common causes of aggravation the police officer suggested noise first and then listed an assortment of: "minor criminal damage, alcohol related disorder, throwing things around in the street, problems with refuse, anti-social behaviour in relation to parties outside, urinating, occasionally defecating". In terms of councillors' case-loads the two big issues regarding students were noise and bins.

Expressing exasperation at being 'displaced' (Hubbard, 2013), the most openly antistudent respondent described how his own leisure activities were constrained because of "the Viz type characters that spill off the pavements and fall onto the road drunk". In describing what Chatterton (1999) refers to as 'geographies of exclusion', he explained how he felt he had to go elsewhere so that he would "not get insulted by rude, pissed students". As the police officer responsible for student liaison recognised, the pressure is not restricted to the weekend:

In other communities you might have alcohol related problems on a Friday night, Saturday night, sometimes Sunday afternoon, but in the community around a university it's Monday to Sunday every week potentially, because students socialise quite intensively during the week

Even those who were unaffected could appreciate the position some residents find themselves in, feeling 'invaded'. One local businessman observed:

If you're a pensioner and lived in Headingley all your life in a street that's suddenly got bought up by fairly aggressive student landlords I can understand there's a situation there that's difficult. I suspect the answer to it was having to move out, but that's distressing for an old person who's lived in Headingley all their life and doesn't want to move but is surrounded by young 
people, some of whom are irresponsible, some of whom are making the mistakes that young people make when you are eighteen, you are away from home, you can go out, you can get drunk and you don't give a damn about people around you, all that sort of stuff which is fairly normal growing up type behaviour. [Chris]

Reg described life as "an absolute nightmare for anybody living next to a student house". Apart from noisy house parties there was the "noise from their parties in their gardens and in the street and noise with students coming back from town going through the streets kicking up a racket, knocking over the bins, shouting, singing". For the benefit of those not living with it, Sue explained:

You've got the in-house noise where people just come in from clubbing at three and slam doors and whatever, you've got the all night parties where you buy in a DJ and industrial strength deck, where the bass in fact travels several houses along... Another problem is when people are going out clubbing, so they have a few bottles first... and because they are quite pissed they don't actually realise how loud they are being...

A councillor observed that simply by having eight people living next door rather than a family of four there is going to be more noise. This is exacerbated by the mismatch in daily patterns; their daily rhythms (and probably musical tastes) are just not "in synch". And two of the councillors recalled separate incidents in which they feared for the mental wellbeing of constituents. One recounted:

I've had constituents in tears driven far beyond what they should have to tolerate... This group of young people simply would not modify their behaviour and every complaint amplified their behaviour. It was unforgivable what they did to this poor woman. Her life was made hell and what do you say when you've got someone sobbing uncontrollably in front of you? ... deliberately misbehave knowing that it makes your life worse in fact we're going to make it worse to see how you react. That's verging on mental torture.

At such extremes these may only be occasional events, but the hurt and pain was genuinely felt and, significantly in this context, communicated to other residents.

Alcohol, along with "juvenile thoughtlessness", was held to be a contributory factor in other nuisances: noise, aggressive behaviour, minor vandalism (e.g. smashed wing mirrors, overturned bins) and littering. There were other aggravations that were almost certainly attributable to people getting "off their heads", like the vomit, and some that were not, like unkempt properties. Bob certainly attributed much of the anti-social behaviour to "the long hours bars stay open". For the first time in recent years he had recently phoned the council because: "Four times in the last ten days we've been woken up at one o'clock, two o'clock, five o'clock and three o'clock ... they were just shouting all the time in the street. I think it's when they come back from clubs..."

Unsurprisingly, business owners were torn between liking the presence of students and fearing their absence (lack of custom) during the vacations. Despite his 
comment above, Chris and the other business owners were less agitated about student behaviour. For example, Keith's assessment was that:

You do see occasionally early on a Saturday morning when they've come out of the bars and that, there's chip papers about, and spots where they've had too much to drink and there's sick or whatever. Then again it's not that big a problem; there's not windows smashed or anything like that.

A smaller number of the residents in the research were largely unconcerned by the presence of students other than the environmental impact of properties being uncared for. Sometimes unexpected benefits were identified, like Victoria whose children loved seeing the fancy dress costumes worn on the Otley Run.

Rather different from the daily rhythms identified above, Peter found the seasonal rhythm quite reassuring:

You will go through a period of high intensity student activity which then calms down and then probably peaks again at the end of term and then they go away and you reoccupy the space, and then after a while you get bored with it and think there's not enough people around and it's nice that they then come back again.

\section{Changes}

When students were a relatively small minority self-regulation was more likely in the soft power exerted by residents, who were able to moderate behaviour by determining the dominant culture and expressing disapproval. The population shift around Headingley means that has become harder to do, though some respondents still refer to a process of education. Chris (above) suggested what is witnessed is "fairly normal growing up type behaviour", but that is only part of the story: they are away from the control that might be exercised 'at home' and they are among an uncommonly large number of people in the same circumstances at the same age. A similar point was made by one of the residents comparing the current situation with when he was a student:

I did misbehave myself - not a lot but a bit. Basically the student population was massively outnumbered by the resident population which simply kept a damper on it. But now the student population outnumbers the resident population there is no way in which the residents can put any brake on it. The theory is that by living in the community students learn to become community members from their neighbours, but in south or central Headingley their neighbours are other students - there's nobody for them to learn from. There's a case to be made for studentification leading to infantilisation of behaviour. [Reg]

As suggested by that quote, those interviewed were invited to reflect on whether the behaviours they now complained about were any different when they were students. Recognising that as a student he was "a fairly common oik" who might also have got 'legless', Len agonised over his judgement: "Am I being too harsh? Am I blowing it all up? Do they behave worse than I did? ... Yes, by and large, yes they do." He 
and others were in effect wrestling with the tension that Hubbard (2013) identified as a struggle to distinguish between acceptable and unacceptable behaviour, civilised and uncivilised bodies.

As Rachel recalled:

The last bus was 11 o'clock so you were at home tucked up in bed mostly. There just wasn't the culture was there? Nothing was open. I can remember walking around town with my friend at 11 o'clock at night saying, 'why is everything closed?' Now I only wish it was! So, yeah, there were just, fewer of us... We weren't even adults. We were in lodgings with the landlord in loco parentis' shouting 'come on, let's have you now, it's past 11 o'clock'. It's just a different world.

Chatterton (2010) also points to the growth of easy credit that has underpinned the growth of the consumption-oriented student city. Clearly 'times change'. Len attributed what he observed to "a change in society's morals and behaviour", and one of the councillors noted cultural shifts and identified the resurgence of "the alcohol economy" as a cause for concern: "these youngsters have a commitment for alcohol that I couldn't match or want to match". Having recounted the decline, Peter thought that "possibly student behaviour has improved over the last four years, partly to do with the economic climate; they haven't necessarily got quite as much to spend". Moreover, there is some evidence to suggest that despite popular opinion young people today are less prone to 'binge drinking' than previous generations (McCoy and Nieland, 2011).

Times change on a different cycle too; as the police officer observed: "you might get a different group of people coming in who are also students but don't make any noise, don't drink as much, don't create the problems that the last crew did". This turnover reflects student transience which means they have little investment in the area. Recognising this, the Students' Union representatives were keen to encourage students to develop some identification with the area and improve social interaction. The transience of the population undermines the formation of community ties and the student liaison officer also suggested the presence of students tends to encourage short-term rather than long-term investment decisions; hence for example, the unkempt nature of some of the houses, which is the responsibility of landlords.

In talking about the transformation of certain neighbourhoods respondents evoked the language of urban ecology, particularly succession. For example, a former councillor recalled how "a few houses would go and suddenly a whole road would because families didn't want to live there". What had felt like a balanced community "suddenly felt like a student ghetto... people were moving out because they couldn't take it any longer". Similarly, Peter explained how one terrace had "collapsed very, very suddenly" because a "bad experience with one group of students" had resulted in "a whole domino effect" (note the geopolitical connotations"). And Len likened it to a military operation, talking about his road being "on the front line" in that it is all owner-occupied, but streets around him are dominated by students. He had talked recently with a neighbour about "creeping studentisation and her view was, 'I'm not giving in; I'm staying put'. Good lass, we shall dig in." 


\section{Control}

Some students try to resist the imposition of deviant identities and assert the normality of their conduct (Garland 2008: p. 17). As the student liaison officer from the police appreciated, the real aggravation amongst local residents relates to having the power to determine the nature of the local community wrested away from them. He suggested: "For them it's a problem of identity in terms of the nature of the area and how it's changed and they often resent that". Peter was more prosaic: "They sometimes say when they become argumentative, 'Headingley belongs to the students now'. No it fucking doesn't!" Other residents were particularly aggrieved that Unipol (the student accommodation agency responsible to Leeds Beckett and Leeds Universities) had identified their area as a student village ${ }^{8}$, and furious with landlords who had told prospective tenants that as it was a student area they could do what they liked.

Rather than spatially defined communities, what are being revealed here are the 'imagined' and 'imaginary' communities of Anderson (1983) and Cohen (1985) whereby communities comprise populations which share meanings such that members are linked together within boundaries created by those understandings. Different 'communities' may therefore exist in the same neighbourhood.

[These] boundaries consist essentially in the contrivance of distinctive meanings within the community's social discourse. They provide people with a referent for their personal identities (Cohen, 1985, p. 117).

Peter continued: "I have a stake, that's right, and therefore I will, as all societies do at whatever level of society, they try to get other people to conform to a social norm and of course I will attempt that". At an even more personal level one respondent resented what these changes meant for her identity because she feels she has been: "turned into a twitching old complainer, which I never wanted to be. Do you know I spend so much of my time writing letters of objection and it's a negative way to live your life, it's not fair."

As can be seen below in relation to assorted policy responses this issue of control recurred.

\section{The Policy Responses}

The third element of Cohen's model outlined above is a recognition of the need for a policy response to public concern.

Some clearly felt that with a shortage in the national housing market it was inappropriate that 'family homes' were being used for student accommodation; worse were properties landlords had turned into HMOs for students but were unlet. Unipol estimated that in 2013 there were at least 4,500 empty bed spaces, estimated to rise to almost 6,000 by 2015 (Jones \& Brown, 2013). From local beginnings in 2000, some of the residents, assisted by the then MP, took a lead in establishing the National HMO lobby. Eventually, in 2010 the outgoing Labour government introduced legislation allowing local authorities to require approval of change of use if someone wanted to convert a house to an $\mathrm{HMO}$ (meaning planning permission could 
be denied). However not long after, the incoming Coalition government decreed that such a change should be regarded as 'permitted development' (no need for permission to change), though more recently still local authorities are allowed to remove such changes from 'permitted development' via the 'Article 4 Direction' in order to prevent communities becoming unbalanced by extreme concentrations of HMOs.

As a way of trying to address what has been seen as irresponsible behaviour by some landlords (and reward good ones) another policy initiative has seen the establishment of a landlord licensing committee, but involvement is not mandatory. Residents, students and councillors all voiced the view that landlords should take a more active role in maintaining a desirable neighbourhood. The local police officer suggested they could combat anti-social behaviour by saying collectively that "if one landlord throws you out, none of the others will take you". Insofar as tales of student misdeeds fuelled an exodus of residents more properties became available for landlords to buy.

The mix of the free market and public policy (expansion of HE, the unwillingness or inability of $\mathrm{HE}$ to provide purpose built accommodation and the introduction of buyto-let subsidies) which had caused the transformation of the housing stock and demographics of Headingley, is now putting a brake on those changes. Not only may some potential students be deterred by the recent shift in HE policy that makes them responsible for the full cost of their education (shorter degrees and distance learning may also reduce numbers), but commercial providers have recognised that they can make a profit from purpose-built student accommodation (PBSA). In the absence of a national policy on student accommodation (Smith, 2008) the private sector has pursued its own policy initiative and built high rise blocks closer to the city centre. It has been estimated that whereas $31 \%$ of students in Leeds were in PBSA in 2007, by 2013 that had become 55\% (Jones \& Brown, 2013). However, having initially been enthusiastic about PBSA, in 2013 Leeds City Council started to question the level of demand and decided they should no longer be operating on the assumption that planning permission should be granted.

Although some respondents clearly consider them inadequate, it is also possible to identify some policies intended to exercise social control. For example, to deal with alcohol-related disorder many of the pubs use licensed door staff, the council has designated a zone of alcohol restraint through a Designated Public Places Order that forbids the drinking of alcohol on the street, and there is a high concentration of CCTV cameras in central Headingley as part of the Safer Leeds initiative (a Crime and Disorder Reduction Partnership). In addition, there is a council policy against granting further alcohol licences in Headingley under a Cumulative Impact Policy.

The policy landscape around both alcohol and housing again raises questions about the locus of power. Councillors of different parties were frustrated about how little control they had. For example, although the council is criticised for having allowed so many licensed premises, one of the councillors insisted that since he had been on the council, every new bar had been opposed, but on appeal to central government had been permitted. Somewhat aggrieved he asked: "What can we practically do? It's not popular explaining to the electorate you cannot solve their problems." A 
former councillor from a different party reflected on supporting residents in resisting an application to convert an empty building into a pub:

We fought that and won, the application was turned down, it went to appeal, it went to London and it went ahead. That kind of thing made it very difficult because you'd fought with local people and thought you'd won, but we couldn't control anything.

She was similarly taken-aback to discover that the council had no powers to stop houses being converted for multiple occupation, and there were not even any proper regulations. She lamented how remedying that:

takes time because you need national legislation to get those powers. It was only when Harold [Best] became an MP that we began to get somewhere regarding HMOs, but it was almost too late by then because we were almost over the worst of it by then.

One of Putnam's (2000) propositions is that linking with others at different levels of the decision-making hierarchy enhances people's social capital. However, despite these various policy interventions, one local activist said that it was as a result of her engagement that she had concluded that "the law doesn't favour residents". She now believes there is little local people can do because:

The laws have been written in support of businesses and moneymaking and however hard you complain as a resident the presumption is in favour of businesses. They are allowed to open their bars until 2 o'clock in the morning, they are allowed to sell people alcohol even when they're already drunk. There's nothing you can do about people walking along past my gate shouting, swearing, vomiting, urinating in my yard, however many times you complain. So when it comes to the planning regulations and the licensing regulations, the presumption is that businesses are allowed to do this.

She illustrated that presumption in favour of business in relation to the policy of no further alcohol licences being awarded in central Headingley, pointing out that: "every time there's an application you still have to write and object to it because if there's no objections then, even though the council has a policy, they will still grant it because there has to be objections in order for them to turn it down".

Although as adults the students are responsible for their own actions, the universities have been responsible for bringing them to Leeds. Councillors shared the view of some residents that the universities had been slow to react to the concerns of the local community. However, as the universities came to recognise their responsibilities to the community and city in which they are located a policy shift on their part has seen two important initiatives. They now offer a "neighbourhood help line' for residents to report problems that they attribute to students and the two largest institutions have half-funded two police liaison officers (officially termed 'student support officers'). Working in conjunction with the universities and their student unions they combine the role of promoting student safety. Representatives of the student unions were also keen to emphasise the programmes instigated to encourage students to contribute to the area they lived in through voluntary activity. 
It is important to local residents to know that 'something is being done'. That the students are proactive, that there is a phone number for reporting concerns and action will follow and that a police officer will knock on the door of students reported for causing distress, carries important symbolic value.

\section{Re-evaluating Folk Devils}

Naturally there are always changes in the residents of an area, but the story of Headingley was one of rapid change and some elements of 'moral panic' were evidenced as changing market forces in response to national policy shifts disturbed the previous balance. Moral panics essentially reflect (im)balances of power and attempts to (re)gain control.

Some of the five key characteristics of Cohen's model (concern, hostility, consensus, disproportionality, volatility) appear in this case while others do not (see also Goode and Ben-Yehuda, 2009). There certainly does seem to be evidence of concern that the behaviour of students has a negative effect on society that is not restricted to this case study (e.g. National HMO Lobby, 2008). Although some are unperturbed, there is also evidence of a clear division between 'them' and 'us'. However, as the student representatives pointed out, many students also consider themselves the victims of the behaviour to which the residents object. There has been widespread (though not universal) acceptance among residents that student lifestyles represent a real threat to the local community, though this is not endorsed by the business owners interviewed and it is certainly not the case that the 'folk devils' appear weak, disorganised though they may be, by comparison with Cohen's 'moral entrepreneurs'. 'Othered' though they may be, students draw strength from their numbers and the profile of their leisure performances. Cohen insists that his use of 'panic' is not to imply a reaction without due cause, but that the response is 'disproportionate'. However, in cases like this it might be advisable not to arbitrate on proportionality, but to follow Garland's (2008) advice and adopt Durkheim's term of righteous, morally toned, 'passionate outrage'. People are clearly entitled to protest against what they consider to be anti-social behaviour that affects the quality of their life and indeed to take evasive action by moving. As the local business owner, Chris, suggested, moving away offers a sensible solution at an individual level. However, it holds out rather less hope in terms of securing a 'sustainable community' (Smith 2008).

In this case the data base search and contemporary monitoring indicated that the conventional media (press, radio and TV) have not played any significant part in fuelling a panic, though arguably more recently social media have contributed by speeding the dissemination of 'word of mouth'. Far from the volatility of Cohen's moral panic, this case seems to be long-lasting. Reports from councillors, residents and estate agents suggest that the flight in aggregate terms appears to have stopped, though the behaviour of students (or other young people presumed to be students) may still be the cause of individual decisions to move away. Maybe the argument for the moral panic framework is 'behind the curve' in that it might have provided a better fit ten or twenty years ago. However, this observation does not quite substantiate Cohen's proposition of volatility as although those remaining do not fit the mould so well, they use the same moral sentiments to exert pressure on policymakers. 
So today the case for a moral panic in Cohen's terms is questionable though some of the characteristics remain; the argument that students are constructed as 'folk devils' is easier to sustain. In McRobbie's (1994) eyes moral panics serve to build fear in order to provide a counter in defence of the dominant social order. Without gainsaying the affront, pain and dismay that may be caused by anti-social behaviour, perhaps what is most significant is the symbolic representation, indicating that the area no longer 'belongs' to the long term residents; others are moulding what Headingley is. Interestingly, this may have contributed to the energy of those behind the Neighbourhood Design Statement and the Headingley Development Trust initiatives that have established the Heart community centre in a former school and the farmers' market. Such efforts lay down a marker that, though outnumbered, local residents can still shape the nature of the area.

In Cohen's model the media wield power through the ability to shape the moral discourse, even if there are more distant hegemonic forces (Spracklen, 2014). Despite the absence of media power, the different protagonists here still protest their powerlessness. It seems that, lacking any great economic and political power, the main arena left to residents and students in their claims of legitimacy is the symbolic, even though in Bourdieu's conception, symbolic power is the consequence of cultural and economic capital (e.g. Bourdieu, 1989). Some of the symbolic power held by students derives from the negative characteristics ascribed to them by others; what others regard as their offensiveness gives them status. That also leads to the amplification Cohen describes, making an accommodation all the harder. Once the label 'student' has been established in the collective imagination of residents, a noisy party at number 43 or someone being sick on the pavement is no longer an individual event, but part of a more general pattern. It may be the only time that person has been sick through drinking too much or the only party in the house that year, but it is now 'students again' and affirms the categorisation.

Concerns relating to alcohol, noise, littering and what Reg referred to as infantile behaviour all serve to signify the challenge by an 'other' to the established order. The processes observed here are quite unlike those in rural Cumbria researched by Valentine et al. (2008) where the community exercised Foucauldian control (Foucault, 1979). One of the major 'advantages' of being a student in a city like Leeds is that it is possible to escape the control of those who know you; it has many of the hallmarks of liminality. 'Student life' is a liminal space, both temporally and geographically, in which they no longer have to comply with the strictures of their parents or their home communities where they have been known as children, nor for the most part with the strictures of the new career, family or community yet to come. The power that Headingley residents might previously have been able to exercise through community pressure on a minority of students in Rachel's day is no longer available to them. Hence in part the efforts to shape the agenda in policy circles; through attempts to engineer policy shifts they are trying to regain some measure of control. Even if they fail it is a marker that 'we are setting the pace here'.

Unlike some of the hasty, vituperative outbursts on electronic media most of the residents (and councillors) interviewed were at pains to recognise good and bad students at an individual level while still arguing that in the aggregate they changed the nature of the culture and the social processes operating in the area. Valentine 
(2001, p.181) suggests that 'moral panics are related to conflicts of interest and discourses of power'. It is this notion of conflict and power that speaks to the case examined here as an example of the 'moral crusades, symbolic politics and culture wars, where specific social groups engage in moral politics in order to redistribute social status and declare one form of life superior to its rivals' (Garland, 2008, p. 17). Residents and students may both feel distanced from the levers of power, but manage to exert other forms of power to lay claim to the area. They wrestle over what Spracklen (2011 - following Cohen, 1985) identifies as an imaginary community, but they hold different 'imaginaries', seeking to establish appropriate symbolic boundaries.

For the residents, the increased number of students has not simply meant the prospect of more offending incidents, but changed the prevalent norms of the area and the ability to exercise soft power. It might be argued that because of their weight of numbers students have two forms of power: economic and symbolic. The former is not just through spending in the local businesses and on accommodation, but the universities benefit from the attraction of 'party city' as an aid to recruitment. Alongside that, symbolic power is derived from brash, noisy visibility (e.g. the Otley Run and the lettings boards). The residents who left had the economic power to do so. Those who remain variously seek to ameliorate the position by 'educating' students moving into nearby accommodation, invoking existing sanctions or using their links with local decision-makers to try to change policy.

In this case study, the attribution of blame sees students as responsible for 'the student economy' more generally: short term investments, the rundown appearance of the area, the number of bars, takeaways and even charity shops. Like Rachel's frustration with the wider legal system, people cannot see how to tackle the student economy other than by making students responsible even when they recognise the role of others and prevailing social forces. One of the student union representatives was also concerned that, in his estimation, students were expected to work harder at getting on with the local residents than vice versa; needless to say, this was not how the residents tended to see it.

Students do not represent the same physical threat as Cohen's gangs, nor is 'the problem' confined to the public realm of the street, but can be in the home or commercial venues; the threat is constructed as one of invasion and takeover. Studentification is discussed in similar language to the arrival of ethnic minorities in a community with talk of invasion, occupying territory, being forced out, domino effects as streets 'fall', tipped balances, and take-overs. Yet these students should be familiar beings, resembling (grand) sons and daughters and past selves. Eyeing the de-studentification represented by vacant accommodation gives some residents hope for the future, opening-up the possibility that families may move back to Headingley. However, students may be replaced by tenants who are no more appealing to the longstanding residents (e.g. new migrants and benefit claimants). The main process leading to the de-studentification to date in some parts of Headingley, the commercial provision of PBSA elsewhere in Leeds, may though serve to shift the locus of control further away from residents and their council(lors).

\section{Conclusions}


As Rohloff and Wright (2010) imply, the moral panic thesis offers a useful heuristic device, but may obscure the operation of other processes. The case examined here does appear to represent what Cohen (2002, p. xxxi) describes as 'a microphysics of outrage', 'initiated and sustained by wider social and political forces'. Residents, public representatives, officials, business people and students struggle in 'drawing of lines between the permissible and the less acceptable' (McRobbie and Thornton, 1995), but largely without the intervention of mainstream media.

A simplified general theory of locational conflict and policy responses to meet such circumstances would be easy to criticise in light of local circumstances. The approach adopted in this study responds to Bevir's call for a 'bottom up' approach (e.g. Bevir \& Richards, 2009) rooted in the experiences of those trying to make sense of the winds of change experienced on the ground. It has offered 'an analysis of change [ ] rooted in the beliefs and actions of situated agents' (Bevir and Richards, 2009, p. 11). Its contribution to the moral panic debate is in emphasising the importance of being able to take a longitudinal perspective and demonstrating the significance of identifying the interplay of different elements of power.

Rather than 'folk devils', Bourdieu (1989, p. 20) writes of 'folk theories' and how their categories have a constructive power in social space which 'tends to function as a symbolic space, a space of lifestyles and status groups...' Here we have seen the operation of folk theories about the behaviour of students. According to Bourdieu (1989, p. 17), symbolic capital derives from the recognition of the legitimacy of economic and cultural capital, but in the case of Headingley it simply requires the recognition of difference. Indeed, it is the negative attributes attached to the group of 'student' that lends it its symbolic power. While some may exalt in that power as a means of establishing a more lively 'scene', other students try to 'change the categories of perception and evaluation of the social world' (Bourdieu, 1989, p.20) by presenting themselves as community volunteers. The empirical investigations recognise how the presence of a large number of students, and the consequent absence of others, shapes the community. Not only does it make it more 'lively', but the nature of the local economy has changed and two primary schools have closed.

Although the initial indicators were strong, the processes reviewed here do not fully accord with Cohen's concept of a moral panic. There was a panicky flight of families from the large number of students generated by the proximity of three universities. Using Hirschman's (1970) terminology, those who exited (fled) do appear to have cast students in the role of 'folk devils'. Those who have demonstrated a fierce 'loyalty' to the area often show a more ambivalent attitude, but want to exercise their 'voice' to protest and protect their definition of the community. While business interests embrace the student market and some residents are largely unconcerned by the student presence, activists have engaged in a struggle to determine the defining characteristics of the neighbourhood. What we have seen here is that macro-level national policies (relating to higher education and planning/housing) have produced micro-level reactions by individuals, requiring meso-level policy responses. In trying to resolve those tensions residents, councillors, students, business owners and others express their frustration at their lack of ability to exercise control the moral order. 


\section{References}

Allinson, J. (2006). Over-educated, over-exuberant, and over there? The impact of students on cities Planning, Practice and Research, 21(1), 79-94.

Bevir, M., \& Richards, D. (2009). Decentring policy networks: a theoretical agenda. Public Administration, 87(1), 3-14.

Biddle, S., Gorely, T., Marshall, S., Murdey, I., \& Cameron, N. (2004). Physical activity and sedentary behaviours in youth: issues and controversies. Journal of the Royal Society for the Promotion of Health, 124(1), 29-33.

Bourdieu, P. (1989) Social space and symbolic power. Sociological Theory, 7(1) 1425.

Brackenridge, C. (2001). Spoilsports: Understanding and Preventing Sexual Exploitation in Sport. London: Routledge.

Brackenridge, C. (2002). '...so what?' Attitudes of the voluntary sector towards child protection in sports clubs. Managing Leisure, 7(2), 103-123.

Bramham, P., \& Spink, J. (2009). Leeds - Becoming the Postmodern City. In P. Bramham \& S. Wagg (Eds.), Sport, Leisure and Culture in the Postmodern City. Farnham: Ashgate.

Chatterton P, (1999). Exclusive geographies: university students in the city. Geoforum, 30(1), 117-133.

Chatterton, P. (2010) The student city: an ongoing story of neoliberalism, gentrification and commodification. Environment and Planning A, 42(2), 509514.

Cohen, A. (1985). The symbolic construction of community. London: Tavistock.

Cohen, S. (1972). Folk Devils and Moral Panics. St Albans: Paladin.

Cohen, S. (2002). Folk Devils and Moral Panics (3 $3^{\text {rd }}$ edition). London: Routledge.

Crawford, A., \& Flint, J. (2009). Urban safety, anti-social behaviour and the nighttime economy. Crime and Criminal Justice, 9(4), 403-314.

Critcher, C. (2006). Critical readings: Moral Panics in the Media. Maidenhead: Open University Press.

DeJong, W., \& Vehige, T. (2008). The Off-Campus Environment Approaches for Reducing Alcohol and Other Drug Problems. Newton, MA.

Foucault, M. (1979). Discipline and Punish. New York, Vintage Books.

Garland, D. (2008). On the concept of moral panic. Crime, Media, Culture, 4(1) 930.

Goode, E., \& Ben-Yehuda, N. (2009). Moral Panics: The Social Construction of Deviance (2nd ed.). Oxford: Wiley-Blackwell.

Hickey, C., Kelly, P., Cormack, S., Harrison, L., Lindsay, J., \& Light, R. (2009). Sporting clubs, alcohol and young people: enduring tensions and emerging possibilities. (ACHPER) Healthy Lifestyles Journal, 56(1), 17-21.

Hier, S. (2002). Raves, Risks and the Ecstacy Panic: A Case Study in the Subversive Nature of Moral Regulation. Canadian Journal of Sociology, 27(1), 33-57.

Hirschman, A. (1970). Exit, Voice, and Loyalty: Responses to Decline in Firms, Organizations, and States Cambridge, MA: Harvard University Press.

Holt, M. \& Griffin, C. (2005). Students versus locals: young adults' constructions of the working-class Other. British Journal of Social Psychology, 44(2), 241-267.

Hubbard, P. (2008). Regulating the social impacts of studentification: a Loughborough case study. Environment and Planning A, 40 (2), 323-341 
Hubbard, P. (2013). Carnage! Coming to a town near you? Nightlife, uncivilised behaviour and the carnivalesque body. Leisure Studies, 32(3), 265-282.

Jones, H., \& Brown, C. (2013). Student Housing Demand and Supply: A review of evidence. Leeds: Re'new.

Leeds HMO Lobby. (2005). Students \& the Community in Leeds. Retrieved 3rd January 2014, from http://hmolobby.org.uk/leeds/natstudcommresponse.htm

McRobbie, A. (1994). Postmodernism and Popular Culture. New York: Routledge.

McRobbie, A. \& Thorton, S. (1995). Rethinking 'Moral Panic' for multi-mediated social worlds. British Journal of Sociology, 46(4), 559-574.

McCoy, S., \& Nieland, M. (2011). Are drinking habits really changing? A crossgenerational test of the 'new' phenomenon of 'binge-drinking'. Drugs: education, prevention and policy, 18(5), 333-339.

Munro, M., Turok, I. \& Livingston, M. (2009). Students in cities: a preliminary analysis of their patterns. Environment and Planning A, 41(8), 1805-1825.

National HMO Lobby. (2008). Balanced Communities and Studentification: Problems and Solutions. Leeds: National HMO Lobby.

Pearson, G. (1983). Hooligan: A History of Respectable Fears. Basingstoke: MacMillan.

Phipps, A., \& Young, I. (2012). That's what she said: women students' experience of 'lad culture' in higher education. NUS: London.

Putnam, R. D. (2000). Bowling alone : the collapse and revival of American community. New York: Simon \& Schuster.

Redhead, S. (2007). This sporting life: the realism of The Football Factory. Soccer and Society, 8(1), 90-108.

Rohloff, A. and Wright, S. (2010). Moral panic and social theory: beyond the heuristic. Current Sociology, 5(3), 403-419.

Selwyn, N. (2008). 'High-jinks' and 'minor mischief': a study of undergraduate students as perpetrators of crime. Studies in Higher Education, 33(1), 1-16.

Smith, D. (2008). The Politics of Studentification and '(Un)balanced' Urban Populations: Lessons for Gentrification and Sustainable Communities? Urban Studies, 45(12), 2541-2564.

Smith, D. (2009). 'Student geographies', urban restructuring, and the expansion of higher education. Environment and Planning A, 41(8), 1795-1804.

Spracklen, K. (2011). Dreaming of drams: Authenticity in Scottish whisky tourism as an expression of unresolved Habermasian rationalities. Leisure Studies, 30(1), 99-116.

Spracklen, K. (2014). Bottling Scotland, drinking Scotland: Scotland's future, the whisky industry and leisure, tourism and public-health policy. Journal of Policy Research in Tourism, Leisure and Events, 6(2), 135-152.

Strauss, A. L., \& Corbin, J. M. (1990). Basics of qualitative research: grounded theory procedures and techniques. Thousand Oaks, CA: Sage.

Thompson, K. (1998). Moral Panics. London: Routledge.

Valentine, G. (2001). Social geographies: space and society. Harlow: Prentice Hall.

Valentine, G., Holloway, S., Knell, C., \& Jayne, M. (2008). Drinking places: young people and cultures of alcohol consumption in rural environments. Journal of Rural Studies, 24(1), 28-40.

\footnotetext{
1 Volume 6(2) 2014, edited by Karl Spracklen: 'Moral Panics or the Politics of Pleasure? Alcohol and Policy Directions in Tourism, Leisure and Events'.
} 


\footnotetext{
${ }^{2}$ The Leeds club hosting the latter had its licence suspended by the city council after a promotional video had been posted on You Tube in which students joked about raping female students as part of the event: http://www.bbc.co.uk/news/uk-england-leeds-25299530.

${ }^{3}$ Her observation was a comment on the lack of research rather than a denial of the abuse.

${ }^{4}$ As this paper is not a spatial analysis we refer to these areas collectively as Headingley.

5 'HMO' stands for 'house in multiple occupation'. An explanation can be found at:

http://www.leeds.gov.uk/docs/PLN\%2078\%20dwelling\%20houses\%20and\%20houses\%20in\%20multi ple\%20occupation.pdf

${ }^{6}$ Although closely monitored, individual quotes are not used here because they were contributed to a closed forum.

${ }^{7} \mathrm{~A}$ term commonly used by American strategists when referring to states 'falling' to the advance of communism.

8 Unipol does in fact offer advice on living with neighbours

(http://www.unipol.org.uk/advice/students/living-in-leeds), but there is no necessary reason why students would know it was there.
} 